\title{
BASES CONCEPTUALES PARA COMPRENDER LA IMPORTANCIA DEL TERRITORIO EN LA CONFORMACIÓN DE LA IDENTIDAD: EL CASO DE SAN RAFAEL DE ESCAZÚ
}

\section{CONCEPTUAL BASIS TO UNDERSTAND THE SIGNIFICANCE OF TERRITORY IN THE CONFORMATION OF IDENTITY: THE CASE OF SAN RAFAEL DE ESCAZÚ}

\author{
Jesús Méndez
}

RESUMEN

\begin{abstract}
En este artículo se muestra la importancia que adquiere el territorio como componente fundamental en la configuración de la identidad de sus habitantes. Se presentan las pautas que permiten comprender el territorio como ese ámbito físico donde se re-producen las relaciones sociales, pero sobre todo, facilita entender la forma en la que es reconocido por sus ocupantes y por extraños como una extensión de la identidad del grupo que lo ocupa, tomando como referencia el distrito de San Rafael de Escazú.
\end{abstract}

PALABRAS CLAVE: TERRITORIO * IDENTIDAD SOCIAL * URBANISMO * RELACIONES SOCIALES * POBLACIÓN

ABSTRACT

This article presents the importance of territory as a key component in the configuration of the identity of its inhabitants. It presents guidelines that allows appreciate the territory as the physical environment where social relations are re-produced, but above all, it lets to understand how is recognized by its occupants and outsiders as an extension of identity of group that lives there, by reference the district of San Rafael de Escazú.

KEYWORDS: TERRITORY * SOCIAL IDENTITY * URBANISM * SOCIAL RELATIONS * POPULATION

Cursando la Maestría en Arquitectura con énfasis en Vivienda y Equipamiento Social de la Universidad de Costa Rica (UCR).

jesmenmu@gmail.com 


\section{INTRODUCCIÓN}

Este artículo es un extracto de la tesis de Licenciatura en Antropología Las Representaciones Sociales de los habitantes de San Rafael de Escazú: su importancia en la determinación de los elementos constitutivos de la identidad de los grupos de altos ingresos económicos, realizada durante el año 2010 y presentada en marzo de 2011. El artículo muestra de manera general, las particularidades que presenta el territorio en la conformación de la identidad, dando como ejemplo el lugar de estudio del texto original: San Rafael de Escazú.

Entre las posibilidades que ofrece este artículo es que permite demostrar la importancia de la relación existente entre el espacio y el grupo que lo habita, lo cual facilita entender el cómo se dan y establecen las simbolizaciones sobre el espacio físico y a partir de allí, constituirse como territorio particular de una colectividad específica, es decir, como lugar donde se pueden reconocer aspectos propios y exclusivos que pueden ser ligados a un grupo con determinadas características, ya sean económicas, étnicas, religiosas, etc.

Esto porque el territorio es un componente esencial en la configuración de la identidad, al estar lleno de simbolizaciones que sus ocupantes realizan al entorno donde se desarrolla su vida. No es simplemente la superficie y los elementos que allí se hayan, tiene también un aspecto abstracto que surge de la incorporación que hacen las personas - los que habitan en este y los que no- de sus construcciones, de sus calles, de sus áreas verdes, de sus ocupantes, etc. A partir de esto el territorio adquiere un atributo intangible que genera valores de pertenencia que permiten identificarlo con una colectividad específica.

Para comprender ese proceso es necesario considerar el territorio como resultado de una serie de mecanismos acaecidos a lo largo del tiempo. Esto porque como espacio físico se encuentra en constante evolución y transformación, por lo que no es posible intentar explicar las características de un territorio basándose solamente en el momento actual, sino también considerando el transcurso que ha permitido su conformación.

\section{RELACIÓN ENTRE IDENTIDAD Y TERRITORIO}

De manera general, la identidad puede ser definida como un proceso que se va construyendo en las interacciones que tienen las personas con los diferentes grupos y contextos sociales con los que se desenvuelven día a día (Méndez, 2011). Surge de la incorporación de una serie de ideas, concepciones, formas de ver, entender $y$ actuar en el mundo que tengan las personas, ya sea como individuos o como parte de un grupo social. Sin embargo, esta identidad no aparece de la nada ni se mantiene estática en todo momento, sino que se encuentra en constante desarrollo, pues las relaciones interpersonales permiten que se vea nutrida de nuevas experiencias que colaboran en su conformación.

A pesar de este continuo cambio, es posible distinguir la identidad de un determinado grupo, pues mantiene un patrón que facilita la diferenciación por contraste o similitud con otra colectividad. Estos procesos no acontecen en el aire, necesitan de un entorno en donde se puedan manifestar, al tiempo que organicen los componentes de la vida diaria de manera específica para cada colectivo (Fernández, 2009). De esa forma, dentro de los códigos que permiten configurar las identidades, se encuentra el espacio, cuya importancia yace:

... en el hecho de que en ellos se desenvuelven la estructura social de los grupos humanos, $y$, por otro lado, a partir de ellos estos grupos sociales construyen buena parte de su universo simbólico, delimitan el territorio, establecen marcas, relaciones materiales y/o simbólicas con la tierra y con el entorno en general, en una continua relación hombre-naturaleza (Galué, 2005: 62).

Todos los grupos sociales tienen la necesidad de simbolizar el espacio, dejar marcas que regulan su uso, nombrarlo y a partir de allí, desarrollar los sistemas que dan paso a los ordenamientos sociales (Ibid.). Por esa razón, es fundamental considerar que el espacio va más allá de la noción de superficie, es decir, la extensión de tierra determinada por las dimensiones 
observables; medible a través de la altura, el largo y el ancho, establecido por puntos cardinales o por relaciones de orden como arriba, debajo, etc. (Bourdieu, 1997: 30). No está dado por la naturaleza, en realidad es el producto de una cultura que da sentido a lo natural, lo que permite la modificación y la adaptación del mismo al proceso social, haciéndolo inteligible para la mayoría de las personas (Fernández, 2009: 111).

Así, el espacio puede ser entendido como la situación física en donde se producen las relaciones sociales (Sánchez, 1979; Ortiz, 1998 y Lefebvre, 2008), partiendo de la concepción de espacio no como cosa, sino como el escenario donde entran en relación los objetos.

El espacio social contiene una gran diversidad de objetos, tanto naturales como sociales, incluidas las redes y vías que facilitan el intercambio de objetos e información. Estos "objetos" no son solo cosas sino también las relaciones. La labor social las transforma, cambiando sus posiciones dentro de las configuraciones espacio-temporales sin que necesariamente afecten a su materialidad, su estado natural (Lefebvre, 2008: 77. Traducción propia) $)^{1}$.

Estos objetos pueden ser tanto naturales (montañas, ríos, zonas costeras, bosques, etc.), como artificiales (edificios, carreteras, etc.). El espacio alberga todos estos elementos, además de la sociedad que en este se asienta. De ese modo, como lo menciona Milton Santos (1986), cada fracción de la naturaleza alberga igualmente una fracción de los grupos humanos.

Para Lefebvre (2008: 110), el espacio no debe verse como el área donde se desarrollan las relaciones sociales en un momento único de

1 Social space contains a great diversity of objects, both natural and social, including the networks and pathways which facilitate the exchange of material things and information. Such "objects" are thus not only things but also relations. Social labour transforms them, rearranging their positions within spatio-temporal configurations without necessarily affecting their materiality, their natural state (Lefebvre, 2008: 77). su historia. Al considerarlo como un mosaico de diferentes épocas, permite apreciar la evolución de la sociedad al tiempo que aclara situaciones presentes en la actualidad que de otra forma resultaría imposible su comprensión. Así, la dimensión espacial guarda una estrecha relación con la dimensión temporal (Lefebure, 2008 y Fernández, 2009), nociones que hasta cierto punto son sumamente abstractas $y$ por lo tanto difíciles de precisar, pero al considerarlas como expresiones de lo real y no como objetos concretos, se facilita su comprensión debido a que lo concreto posee nombre propio, ya sean de lugares, rutas, fronteras, caminos, etc. (Fernández, 2009).

Estos elementos concretos están sometidos a variaciones temporales, por lo que su valor, importancia o significado pueden cambiar según el periodo (Santos, 1986). En otras palabras, todo espacio tiene una historia dotada de características específicas, que se encuentran en una evolución constante resultado de la acción de factores internos y externos, sociales y naturales (Lefebvre, 2008). Es por esta razón que no resulta extraño notar cómo componentes de los lugares como calles, barrios, parques, etc., pueden mantener una misma onomástica a lo largo de los años; sin embargo, el valor o simbolismo asociado a cada uno puede haberse modificado.

Este fenómeno se explica por la relación existente entre los componentes abstractos y los reales, los que al ser interiorizados permiten desarrollar una idea de territorio, que como se verá más adelante, se da cuando se logra la identificación del espacio con un determinado grupo social. Además, es necesario dar cuenta que estos elementos acontecen por lo general, en el interior de lo que se denomina como espacio urbano cuya expresión es la ciudad-y es aquí donde se desarrolla la experiencia social día a día.

\section{IMPORTANCIA DE LA DICOTOMÍA ESPACIO REAL - ESPACIO ABSTRACTO}

Quizás uno de los aspectos que ha sido más examinado por diversos autores (Santos, 1986; Silva, 2000; Galué, 2005; Harvey, 2006 y Lefebvre, 2008), es la dicotomía existente entre el espacio real $y$ el abstracto, precisamente 
al ser perspectivas que determinan en gran medida la caracterización que se pueda realizar del espacio.

El espacio "real", también considerado como "total" (Santos, 1986), "absoluto" (Harvey, 2006) o "concreto" (Galué, 2005); es aquel que está entendido usualmente como el inamovible, lo concreto. Para Harvey (2006) este espacio es pre-existente, en la medida en que se ubica por medio de los sentidos $y$ es capaz de ser comprobado con mediciones geométricas estandarizadas, en un sentido euclidiano. De esta forma, las casas, los apartamentos, los edificios, las fábricas o cualquier otra construcción humana; así como, los bosques, los ríos, las montañas, etc., forman parte de este espacio real. Son las cosas tal como son vistas, reconocidas como objetos que forman parte de la superficie terrestre.

Por otra parte, el espacio "abstracto" (Santos, 1986 y Galué, 2005) o "relativo" (Harvey, 2006 y Lefebvre, 2008), reside en la simbolización que se hace de estos objetos presentes en el terreno. Su importancia no se encuentra en "... la cosa tal como la vemos, sino en su valor relativo dentro de un sistema más amplio" (Santos, 1986). En este sentido, el espacio tiende a ser relativizado dependiendo de la persona que lo interpreta, según sus concepciones $y$ formas de apreciar el mundo que lo rodea.

Ambas concepciones del espacio no son excluyentes entre sí, por el contrario, están presentes simultáneamente. Debido a esto, las personas son capaces de caracterizar determinados lugares en relación a su valor simbólico, lo cual está determinado por los elementos que lo componen ya sea por acción humana o natural, así como, el colectivo que lo habita o que hace de este su entorno específico.

La identificación del espacio determina valores de pertenencia que permiten a los sujetos anclar una cultura específica a ese lugar. Por esta razón, cuando al espacio se le asocia una serie de elementos propios de un grupo social, se convierte en una categoría denominada territorio (Silva, 2000; Oslender, 2002; Kronnerber, 2005; Valbuena, 2005; Delgado M., 2007; Lefebvre, 2008 y Delgado O., 2009), que va mucho más allá de la idea de espacio como situación física donde se producen las relaciones sociales.

\section{CONCEPCIÓN DEL TERRITORIO}

En la medida en que los grupos humanos logran afianzar una identificación con el espacio, este actúa como centro que permite legitimar esa identidad, es decir, un territorio. El mismo facilita la relación y contraste con el medio ambiente, al tiempo que lo hace también con espacios apoderados por otras colectividades.

Para Silva (2000: 50), el territorio es presentado como la exposición de la unidad de un grupo social, es el encuentro de la extensión geográfica y del simbolismo de los elementos espaciales y de sus pobladores. Así, donde quiera que un grupo conforme su territorio, allí están sus símbolos como herramientas de distinción y ordenamiento de la experiencia de vida (Valbuena, 2005: 32).

Es un concepto que va más allá de la idea de espacio, el territorio se ha logrado establecer mediante una identificación social, apropiado por un grupo como específico de su influencia $y$ de sus relaciones. Se puede afirmar que un colectivo culturalmente diferenciado es capaz de lograr esta ocupación del espacio permitiendo “... asegurar su reproducción y la satisfacción de sus necesidades vitales, que pueden ser materiales o simbólicas" (Kronnerber, 2005: 6). Esos colectivos pueden ser cualquier tipo de actores sociales, ya sean pequeñas colectividades ligadas por determinados aspectos en común, hasta estados nacionales, organizaciones, empresas, etc., pues el territorio es la expresión de la identidad $y$ control sobre el espacio:

Territorio se refiere a un espacio de poder, de dominio y de gestión, es decir un espacio geográfico, controlado, apropiado $y$ usado por distintos actores sociales, tales como individuos, empresas, grupos sociales organizados, estados nacionales, organizaciones transnacionales, etc. (Delgado O., 2009: 100).

Siguiendo ese razonamiento, el territorio de las distintas colectividades - sean 
económicas, étnicas, religiosas, políticas, etc. - tienen un umbral, a partir del cual se reconocen estos grupos y las personas que los conforman, ayudando en la configuración y legitimación de la identidad de cada uno de ellos, al tiempo que mantiene coherencia, según el grado de dependencia que alcancen los habitantes con su entorno.

Identidad es por lo tanto un "asegurarse a sí mismo" y para ello necesitamos necesariamente también de un soporte físico que constituya la dimensión externa de esa identidad. Por eso la identidad necesita de un centro a partir del cual se irradia su territorio, esto es, su legitimidad... (Kronnerber, 2005: 6).

No obstante, para comprender realmente un territorio es necesario tomar en cuenta el proceso que lo ha ido conformando, las causas $y$ las consecuencias de las transformaciones de sus componentes ambientales, económicos, sociales y políticos. Esto porque el territorio sigue el ritmo de "... los cambios sociales, la dinámica política, la dinámica económica y las transformaciones culturales, en las escalas espacio-temporales de orden global, nacional, regional y local" (Delgado O., 2009: 100).

Por eso, para entender un espacio como expresión de la identidad del grupo social que lo habita, es necesario considerar su disposición en la totalidad de elementos que lo componen y de allí, se puede dar cuenta de la forma con la que se logra el proceso de identificación, porque cada uno de esos elementos es influyente y específico para cada territorio. Sin embargo, se puede hablar de un aspecto que permite contextualizar muchos de estos espacios sociales con el surgimiento de una identidad moderna, por decirlo de alguna manera. Este es el fenómeno urbano, el cual posibilita comprender una serie de conexiones que dan lógica a las condiciones de vida actuales de los habitantes.

\section{CONFORMACIÓN DEL FENÓMENO URBANO}

Según Mejías (2006), los análisis de los procesos de urbanización por lo general, se han manejado partiendo de perspectivas evolucionistas: la aparición de la ciudad (expresión máxima de lo urbano) se da cuando las sociedades logran complejizarse tecnológicamente, partiendo de un desarrollo de la agricultura que lleva a un aumento de la producción y a un excedente de esta, haciendo posible la concentración de individuos en un mismo espacio.

A partir de esta afluencia de personas dentro de lo que se considera como ciudad, la vida urbana representa un mejoramiento de las condiciones de vida respecto a las zonas pauperizadas del campo (Gravano, 2003: 13). Esto da origen a un fenómeno migratorio que aumenta la población, debido al rango de oportunidades $y$ a la diversidad de bienes $y$ servicios que se incrementan dentro de las urbes, logrando modificar su espacio - tanto el real como el abstracto- con el ingreso de individuos que buscan mejorar sus condiciones de vida.

De manera general, Castells (1973) establece que el término urbano designa la ocupación del espacio por parte de una población, con la particularidad de que su resultado es una elevada aglomeración que deriva en causa y efecto de diferenciaciones sociales $y$ funcionales.

No obstante, ¿cuánta población es necesaria para considerar un espacio como urbano o como no urbano? Es un asunto que deja muchas interrogantes de este aspecto, pues es notable la diferencia que existe entre la ciudad de París, en Francia y la ciudad de San José, en Costa Rica, en cuanto a su dimensión demográfica. Por eso, para poder determinar con mayor precisión cuál espacio puede ser considerado como urbano y cuál no, se contempla también otra característica que permite complementar estas nociones: las ciudades son centros de control político y administrativo. Representan la expresión espacial de una complejidad social determinada por el proceso de apropiación y reinversión del excedente de trabajo (Castells, 1973: 16). No son lugares de producción, sino de gestión y dominación ligados al predominio del aparato político-administrativo.

Más aún, como lo señala Castells (Ibid.), el conocimiento generalizado de lo urbano se basa en tres supuestos: 
$\diamond \quad$ La existencia de un determinado sistema de producción: que sería primordialmente industrial, lo agrícola y ganadero queda ligado más que todo al campo.

$\diamond \quad$ Un sistema de valores universal: guiado por la creencia del desarrollo progresista, generando valores de índole modernistas. $\diamond \quad$ Una forma particular de ordenamiento espacial: la ciudad, en donde sus características más exclusivas son la dimensión y la densidad.

Más allá de sus características, la ciudad es un espacio social que llega a ser territorio por medio de construcciones simbólicas que sus habitantes y las personas externas realizan sobre esta. Estas construcciones son configuradas dentro de lo que varios autores (Gravano, 2003; Kronnerber, 2005 y Mejías, 2006) denominan como "imágenes urbanas", que específicamente ofrecen a los sujetos las posibilidades de comprender la identidad de los individuos ligado al territorio que ocupan.

\section{FORMACIÓN DE LA IMAGEN URBANA}

Para Kronnerber (2005), la imagen urbana puede definirse como el sustrato mental de lo que el ser humano ha logrado abstraer de la realidad física, según sus perspectivas determinadas por intensiones conscientes e inconscientes; pasa a ser la "realidad urbana" del ciudadano, fijado por la representación mental y emocional de su entorno físico. Surge de la síntesis realizada por los individuos mediante procesos perceptuales de las características, actos o condiciones del entorno temporal, físico-geográfico y humano de la ciudad (Mejías, 2006). Además, es el producto de la recreación mental de las imágenes, asociaciones, recuerdos, elementos, símbolos, espacios y actividades humanas en un determinado momento histórico.

Son estas imágenes las que permiten a los actores sociales re-crear y re-conocer el ámbito de validez de su territorio (Gravano, 2003), donde se registran las relaciones y normas conocidas, logrando la afirmación de su lugar propio. Como se mencionó anteriormente, este reconocimiento no se hace solamente a partir del componente objetivo - lo estructural de la ciudad - sino también de los acontecimientos que le transcurren y le dan vida (Mejías, 2006: 27), es decir, las relaciones humanas que acontecen en su interior.

A la imagen urbana - la identificación de la ciudad ligada al grupo que la habitase le ven atribuidas tres cualidades esenciales que permiten determinarla: la temporalidad, la espacialidad y la culturalidad (Mejías, 2006).

Cuando se hace referencia a su cualidad "temporal", se reconoce que la imagen urbana cambia según el momento histórico en la que es producida y percibida. Está determinada por las diferentes tendencias generacionales, los diversos periodos de desarrollo político y económico, así como, las variaciones físicas y ambientales. Por ejemplo, no es lo mismo una imagen urbana de un San José de principios de Siglo XIX, con poca cantidad de tránsito vehicular, unos miles de habitantes y una economía basada en la exportación cafetalera en muchos lugares; a una imagen de San José a principios del Siglo XXI, donde existe una crisis vial por el incremento desmesurado de los automóviles, así como, una explosión demográfica considerable y una economía basada en el turismo.

La cualidad "espacial" de la imagen urbana hace referencia a su condicionamiento según las variables geográficas propias de su ubicación, determinada incluso por aspectos geomorfológicos. No es lo mismo la representación que pueda obtenerse de una ciudad costera, determinada principalmente como destinada al turismo, a una ciudad en el interior, la cual se consigna para la producción de alimentos o la gestión del país.

Finalmente, la cualidad "cultural" indica que la imagen urbana está determinada por factores étnicos, culturales y económicos propios de la sociedad o grupo social que establezca el territorio. Cuando se hace referencia a dos sociedades en un nivel sincrónico y aunque las características geográficas sean casi idénticas o próximas, la imagen urbana de cada una de ellas puede mostrar grandes diferencias, según el grupo humano establecido en cada espacio.

Estas cualidades permiten establecer diferencias notables entre las imágenes urbanas. No se muestran de manera aislada, sino que se articulan 
y pueden ser apreciadas de manera armónica mediante la configuración y lectura de todos los elementos constituyentes de la ciudad, así como, la forma en que el observador entabla las relaciones con la misma (Mejías, 2006).

Por esa razón, la ciudad aparece como una inmensa red simbólica en permanente construcción y expansión (Silva, 2000: 23). Esto permite que cada ciudad se parezca a sus creadores, a la vez que estos son identificados con su ciudad, relación que se mantiene en una constante transformación, pues las ciudades al igual que las personas que las habitan, se ven nutridas de diferentes experiencias en el vaivén de los diversos contextos sociales.

\section{ESCAZÚ COMO TERRITORIO DE GRUPOS DE ALTOS INGRESOS ECONÓMICOS}

Recuperando lo anteriormente mencionado, el territorio tiene la particularidad de ser un reflejo del grupo social que lo habita, al tiempo que delimita a esa población como poseedora de identidad mediante la imagen urbana. El territorio, por tanto, constituye $y$ es constituyente a la vez de las simbolizaciones que se tengan sobre un colectivo.

En el caso que concierne a la investigación de la cual parte este artículo, se considera que el cantón de Escazú, en general, ha sido popular y estatalmente identificado durante los últimos 30 años con una imagen urbana caracterizada por la presencia mayoritaria de personas con altos ingresos económicos - contrario a la anterior imagen asociada con el folklor de boyeros, trapiches y cafetales. Esta correspondencia es realizada sin importar la condición de las personas entrevistadas, es decir, no importa la condición económica o social, frecuentemente tienden a realizar esa asociación, máxime al hacer referencia al distrito de San Rafael.

A pesar de esta identificación con un determinado grupo y contrariamente a lo que se establece a nivel mediático o popular, se reconoce que en la realidad Escazú presenta también personas de niveles socioeconómicos muy bajos. Es a partir de este enorme contraste entre la realidad y la representación del cantón que se tiene a nivel nacional -incluso internacionalque se presenta una interrogante: ¿qué factores han propiciado para que Escazú sea considerado como territorio específico de personas con altos ingresos en general, a pesar que se pueden encontrar otros grupos?

Para entender la razón, es necesario recordar que el cantón es primordialmente un espacio y como tal, posee características de lo real y lo abstracto que se ven nutridas de factores internos y externos, que producen allí una evolución constante de particularidades identitarias que le son conferidas.

Como se ha mencionado anteriormente, no es posible entender el territorio, en este caso de Escazú, tomando en consideración únicamente el momento actual, debe ser visto como un proceso que se ha dado a través de los años, involucrando los aspectos históricos, demográficos, ambientales e infraestructurales - tanto comerciales como habitacionales- presentes en el cantón; que dan paso a la conformación de las representaciones que se forman sobre el espacio y sus habitantes.

En el aspecto histórico, el lugar que hoy se conoce como Escazú fue primordialmente un lugar de paso y descanso durante la época precolombina y fue hasta el año 1600, cuando llegaron los primeros colonos. A partir de ese entonces se fueron aglomerando en la zona europeos y mestizos que desplazaron a los indígenas que aún se mantenían en la región.

El crecimiento de la zona fue similar a la del resto del país, hasta que entre los años 1832 y 1843 se produjo la expansión cafetalera en la Depresión Central, siendo Escazú uno de los sitios que se aprovechan para esta actividad. Este hecho marca el uso, el desarrollo y la economía de la zona, pues muchos terrenos baldíos son apropiados por los productores del grano como iniciativa del gobierno de turno.

Esto transcurre hasta mediados del siglo $\mathrm{xx}$, cuando se da una importante caída en el valor del café y los propietarios de las tierras deciden darles otro uso. A partir de ese momento, cada uno de los distritos del cantón toma un rumbo histórico diferente.

En San Antonio, se logran conservar familias dedicadas a labores relacionadas al campo como ganaderos, agricultores y a la producción en trapiches. El centro, por otra parte, 
parece conservar al menos su estructura fundamental como cabecera del cantón, ya que desde mediados del siglo anterior no se han visto cambios significativos en su ordenación. Estos dos distritos parecen distar de la imagen urbana que se da a nivel nacional, determinada como lugar donde primordialmente habitan personas de condiciones económicas y sociales altas.

En su desarrollo histórico, es San Rafael el que permite aclarar por qué se genera esa representación, pues la conjunción de variables económicas, demográficas, climáticas y la evolución de la infraestructura ayudaron a que este distrito sea el punto de referencia del cantón en sí. Este cambio se generó precisamente cuando los terrenos anteriormente destinados a la siembra del café, se vieron segmentados por sus dueños para diversos fines, ya fueran comerciales o habitacionales. Trejos Montealegre fue la familia que empezó con esta tendencia, pues en la propiedad anteriormente dedicada al beneficio, hoy se encuentra una de las urbanizaciones y centros comerciales más importantes del cantón, incluso a nivel nacional.

Otro lugar importante es Guachipelín, que pasó de ser una zona considerada como pantanosa, arcillosa y no apta para la agricultura, a un lugar con una de las mayores plusvalías del país, primordialmente por a la distribución de agua potable desde Puente de Mulas, que aunado al desarrollo que tenía el distrito debido a Trejos Montealegre, empezó a atraer gente que buscaba lugares para el descanso o terrenos amplios donde construir sus viviendas.

Estimulados por el surgimiento de estos dos principales centros de población adinerada, el distrito fue desarrollando una serie de lugares que empezarían a albergar con mayor importancia personas de condiciones económicas altas; con lo cual, la representación de San Rafael se va reafirmando poco a poco, ampliando su imagen a todo el cantón, a pesar que se daba primordialmente en el distrito.

En el aspecto ambiental, las propiedades climáticas y geográficas hacen del cantón un lugar ameno para aquellas personas que buscan un descanso o tener a simple vista un escenario paisajístico como los Cerros de Escazú. Por esta razón, muchas personas con capacidades eco- nómicas elevadas adquieren terrenos o condominios en la zona, ubicándose en zonas de alta plusvalía que permiten aprovechar ese entorno.

Respecto al aspecto demográfico, Escazú ha tenido a lo largo de su historia, un incremento moderado, con épocas en las cuales aumenta el número de habitantes de manera vertiginosa. Una de estas épocas, alrededor del año 1950, se da cuando el café pierde su valor $y$ los propietarios de las tierras deciden transformar los terrenos en unidades habitacionales y comerciales; junto con las condiciones climáticas, el abaratamiento de la tierra y la cercanía con la ciudad capital, atrae a una enorme cantidad de personas; duplicando la población durante un periodo de 13 años.

Este aumento en la cantidad de habitantes está ligado también a la llegada de una gran cantidad de extranjeros. Algunos con grandes posibilidades económicas que buscan un lugar de descanso o donde realizar inversiones y otros sin dinero, que buscan formas de ganarse la vida en un lugar donde la construcción y el servicio doméstico son fuentes importantes de recursos.

Además, como parte del aspecto demográfico que hace de Escazú territorio de alta valía y por ende, de alto estatus, es la gran cantidad de personalidades que se han ubicado en el cantón, ya sean políticos, científicos, embajadores, etc. Esto lo hace atractivo como lugar donde individuos con condiciones semejantes pueden acercarse, en un ambiente diseñado para su seguridad y goce. Finalmente, el aspecto que más desarrollo ha sostenido, principalmente en los últimos 15 años, es la infraestructura habitacional y comercial. Ha tenido lugar, especialmente en San Rafael, donde se ha considerado como "zona rosa" 2

$\overline{2}$ La Zona Rosa es el nombre que recibe la antigua Colonia Americana en la Ciudad de México, llamada de esa forma en 1967, porque en su apogeo en las décadas de 1950 y 1960, las viviendas se vieron influenciadas por el estilo francés, donde además se ubicaron familias adineradas, diplomáticos estadounidenses y alemanes, librerías con inclinaciones bohemias, galerías de arte y joyerías (Pantoja, 2007). A partir de esta primera Zona Rosa, se le llama así a lugares donde se dan grandes concentraciones de establecimientos destinados a un público con grandes capacidades económicas. 
por la alta concentración de comercios cuyo público meta son las personas con mayores posibilidades económicas.

Este desarrollo se da como resultado de una serie de factores que se mantienen relacionados: el primero, es la caída del café alrededor de mediados del siglo anterior, la cual genera la pérdida del valor de los terrenos, por lo que los propietarios deciden realizar una segmentación $y$ destinarlos a vivienda $y$ comercios; un segundo factor, se da a comienzos de la década de 1970, con la construcción de la carretera a Orotina que trajo como resultado la expansión del casco urbano; el tercer factor que permite el crecimiento de la infraestructura, es la apertura de Multiplaza a principios de los 90, generando una puerta de entrada a muchos comercios y empresas que no se encontraban en el país; finalmente existe un cuarto factor, que se da como resultado de la apertura del crédito bancario destinado a la vivienda, lo cual permite que muchas personas, con o sin recursos, puedan hacerse de un terreno o construir una vivienda.

Una de las características principales de la infraestructura que se ha desarrollado en San Rafael de Escazú, es el auge de unidades habitacionales llamadas condominios, caracterizados por ser propiedades con varios dueños. Muchos de estos poseen un elevado precio, por lo que solamente ciertas personas con solvencia económica pueden adquirirlos, lo que refuerza la idea de territorio de grupos adinerados.

Los condominios ofrecen principalmente tres ventajas: la alta seguridad, pues cuenta con murallas que impiden el acceso a particulares, así como, guardas particulares situados a la entrada; muchos tienen recreaciones además de los bienes y los servicios disponibles solamente para los habitantes, lo cual permite el desarrollo de un estilo de vida y por último, el prestigo al dotar a los condóminos de cierto estatus al ser diseños extranjeros, principalmente norteamericanos.

La conjunción de los aspectos históricos, ambientales, demográficos e infraestructurales hacen de Escazú un lugar codiciado por personas con posibilidades económicas altas, quienes se ven atraídas por las condiciones y facilidades disponibles. Este acercamiento se lleva a cabo, debido a que ya existe todo un mosaico de particularidades que hacen posible reconocer a Escazú como espacio social específico de los sectores más pudientes y al mismo tiempo, con la llegada de más personas que reúnen estas condiciones se va reforzando constantemente esta identificación. Esto permite denotar la importancia que adquiere el territorio en la conformación de la identidad del grupo que lo habita, al tiempo que permite responder la pregunta planteada, al conocer los factores que inciden en que el territorio de Escazú sea característico de estas colectividades.

\section{CONCLUSIONES}

A lo largo del artículo se presentan las características por las que el territorio juega un papel importante en la conformación de la identidad de los grupos que lo habitan. La primera noción que se debe considerar es la del espacio, la cual, más allá de ser simplemente la superficie donde se disponen los elementos que conforman las ciudades, es en sí mismo un escenario donde entran en juego los diferentes actores sociales, sean individuos o colectivos.

El espacio se encuentra en constante transformación, pues es un mosaico de procesos que se han dado en determinados momentos históricos. Comprenderlo de esa manera da paso a facilitar el entendimiento de su conformación actual y solo así poder explicar cómo es establecido y vislumbrado por sus habitantes, así como, por los extraños a estos. Esto se logra revelar, al dar cuenta que el espacio se ajusta según los componentes reales y abstractos que permiten a las personas realizar simbolizaciones, las cuales están estrechamente relacionadas a la población que allí se asienta.

En este caso, los aspectos históricos que dieron paso a la conformación de lo que hoy se conoce como Escazú, permite dar cuenta de esta transformación al tiempo que facilita entender por qué Escazú es identificado actualmente con una colectividad específica, siendo también ese espacio reflejo del grupo social.

Cuando esa simbolización se realiza y es posible relacionarla con una colectividad específica, el espacio adquiere una connotación mayor, pasa a ser territorio, es decir, se ha 
logrado establecer mediante una identificación social con un grupo. Esto genera en las personas una serie de imágenes urbanas, con las cuales es posible anclar de manera casi inequívoca ese lugar como ámbito particular y a la vez distintivo de un grupo social, tal es el caso, de Escazú cuando ciertamente se identifica en el discurso nacional como propio y particular de los sectores de altos ingresos.

Las imágenes urbanas son desarrolladas de maneras distintas por las personas, pues en su formación influye la manera en la que cada individuo logra entender los fenómenos que se dan a su alrededor. Sin embargo, es posible encontrar situaciones en común, con lo cual se logran establecer pautas que permiten dar cuenta de una identificación del territorio con sus habitantes. Pero al ser un proceso dialéctico, no solo el espacio se ve relacionado a una población, sino que también ese colectivo y las personas que lo integran son identificadas al territorio, con lo cual se comprende la importancia que adquiere el territorio en la conformación y determinación de la identidad.

Por esa razón, las investigaciones que busquen abarcar la conformación de la identidad de determinado grupo deben tener en cuenta el espacio donde se ubican. Comprender la forma de apropiación de este permite manejar y alcanzar de manera más holística el proceso de formación de identidad y con ello entender cómo se manejan las personas en el mundo.

De acuerdo a lo expuesto en este artículo, comprender el proceso que ha ido conformando el territorio apropiado por determinado grupo social, permite dar paso al conocimiento de este colectivo. Por tal razón, vislumbrar a futuro investigaciones sobre territorios como Los Guido, León XIII, Desamparados, los Hatillos, Santa Ana, Pavas, Jacó, entre muchos otros, es esencial para abarcar de manera mucho más integral el estudio de las poblaciones que en ellos se encuentran.

\section{BIBLIOGRAFÍA}

LIBROS Y REVISTAS

Bourdieu, Pierre. Capital cultural, escuela y espacio social. México DF: Siglo XXI Editores, 1997.
Castells, Manuel. La cuestión urbana. México: Editorial Siglo XXI, 1973.

Delgado, Manuel. La ciudad mentirosa. Fraude y miseria del "Modelo Barcelona". Madrid, España: Editorial Catarata, 2007.

Delgado, Ovidio. "Geografía y Ciencias Sociales. Una relación reexaminada”. Geografía Humana y Ciencias Sociales. Una relación reexaminada. Cháves, Martha; González, Octavio y Ventura, Ma. Del Carmen (eds.). México. El Colegio de Michoacán, 2009: 91-106.

Fernández, Federico. “¿Quién estudia ese espacio? Una reflexión sobre la Geografía y los intereses de las Ciencias Sociales". Geografía Humana y Ciencias Sociales. Una relación reexaminada. Cháves, Martha; González, Octavio y Ventura, Ma. Del Carmen (eds.). México. El Colegio de Michoacán, 2009: 107-132.

Galué, Iván. "El saladillo: códigos espaciales y religiosos en la re-creación de las identidades urbanas". Antropología, cultura e identidad. Leal, Morelva y Alarcón, Johnny (comps.). Maracaibo. Universidad del Zulia, 2005: 51-86.

Gravano, Ariel. Antropología de lo barrial. Estudios sobre producción simbólica de la vida urbana. Buenos Aires: Espacio Editorial, 2003.

Harvey, David. Spaces of global capitalism: towards a theory of uneven geographical development. London: Verso, 2006.

Kronnerber, Igor. "Planificación de la imagen urbana”. Seminario Planificación de la Imagen Urbana. San José, Costa Rica: Escuela de Arquitectura, Universidad de Costa Rica, 18-22 de abril de 2005.

Lefebvre, Henri. The production of space. Blackwell Publishing, 2008.

Mejías, Rodolfo. "La construcción de la imagen urbana. Formas, espacios y vivencias urbanas. La calle central de la ciudad de San José". [Tesis para optar por el grado de Magister Scientiae en Diseño Urbano]. San José: Ciudad Universitaria Rodrigo Facio, 2006.

Méndez, Jesús. "Las representaciones sociales de los habitantes de San 
Rafael de Escazú: su importancia en la determinación de los elementos constitutivos de la identidad de los grupos de altos ingresos económicos". [Tesis de Licenciatura en Antropología Social]. San José: Ciudad Universitaria Rodrigo Facio, 2011.

Ortiz, Renato. Otro territorio: ensayos sobre el mundo contemporáneo. Buenos Aires: Convenio Andrés Bello, 1998.

Silva, Armando. Imaginarios urbanos. Cuarta edición aumentada. Bogotá, Colombia: Tercer Mundo Editores, 2000.

Valbuena, Carlos. La casa y la calle como espacios festivos. Antropología, cultura e identidad. Leal, Morelva y Alarcón, Johnny (comps.). Maracaibo: Universidad del Zulia, 2005: 29-50.

\section{DOCUMENTOS DE PÁGINAS WEB}

Oslender, Ulrich. "Espacio, lugar y movimientos sociales: hacia una 'espacialidad de resistencia'”. Scripta Nova. Revista electrónica de Geografía y Ciencias Sociales VI (115). 1 de junio de 2002.
[Revista en línea]. En: <http://www.ub.es/ geocrit/sn/sn-115.htm>. Consultado el 4 de setiembre de 2010.

Pantoja, Sara. "Treinta años de deterioro en la Zona Rosa". Buscador de Arquitectura. 27 de noviembre de 2007. En: <http:// noticias.arq.com.mx/Detalles/9559. html>. Consultado el 24 de agosto de 2010.

Sánchez, Juan. "Poder y espacio". Geocrítica. Cuadernos Críticos de Geografía Humana 23. Setiembre de 1979. [Revista en línea]. En: <http://www.ub.es/geocrit/ geo23.htm $>$. Consultado el 10 de setiembre de 2010.

Santos, Milton. "Espacio y método". Geocrítica. Cuadernos Críticos de Geografía Humana 65. Setiembre de 1986. [Revista en línea]. En: <http://www.ub.es/geocrit/ geo65.htm>. Consultado el 28 de agosto de 2010 .

Fecha de ingreso: $10 / 05 / 2011$

Fecha de aprobación: 30/07/2011 
